\title{
Moral Reasoning Memoderasi Pengaruh Ethical Sensitivity Pada Kualitas Internal Audit di PT. Bank BRI Kantor Cabang Se-Provinsi Bali
}

\author{
Ida Ayu Pradnyani Wedhasari ${ }^{1}$ \\ Ida Bagus Putra Astika ${ }^{2}$
}

${ }^{1}$ Fakultas Ekonomi dan Bisnis Universitas Udayana (Unud), Bali, Indonesia email: idaayupradnyaniwedhasari@gmail.com/ Telp : +6282144949713

${ }^{2}$ Fakultas Ekonomi dan Bisnis Universitas Udayana (Unud), Bali, Indonesia

\begin{abstract}
ABSTRAK
Audit internal merupakan fungsi penilaian independen dalam suatu organisasi untuk menguji dan mengevaluasi kegiatan organisasi yang dilaksanakan. Tujuan penelitian ini menganalisis moral reasoning memoderasi pengaruh ethical sensitivity pada kualitas internal audit di PT. Bank BRI Kantor Cabang se-Provinsi Bali. Penelitian dilakukan di PT. Bank BRI Kantor Cabang se-Provinsi Bali, menjadikan auditor sebanyak 50 orang sebagai sampel melalui metode sample jenuh. Pengumpulan data dilakukan dengan menyebarkan kuesioner sebanyak 50 responden, di uji melalui teknik moderasi regresi analisis.Berdasarkan hasil analisis, variabel ethical sensitivity berpengaruh positif pada kualitas internal audit di PT. Bank BRI Kantor Cabang se-Provinsi Bali. Moral reasoning memoderasi pengaruh positif ethical sensitivity pada kualitas internal audit di PT. Bank BRI Kantor Cabang se-Provinsi Bali.

Kata kunci: ethical sensitivity,moral reasoning, kualitas internal audit
\end{abstract}

\begin{abstract}
Internal audit is an independent appraisal function within an organization to test and evaluate the organization's activities. The purpose of this study to analyze the moral reasoning moderate the influence of ethical sensitivity on the quality of internal audit at PT. Bank BRI Branch Office of Bali Province. Research conducted at PT. Bank BRI Branch Office of Bali Province, making auditor as much as 50 people as sample through saturated sample method. Data collection was done by spreading questioner as much as 50 responders, tested by regression analysis moderation technique. Based on result of analysis, variable of ethical sensitivity have positive effect on internal audit quality at PT. Bank BRI Branch Office of Bali Province. Moral reasoning moderates the positive influence of ethical sensitivity on internal audit quality at PT. Bank BRI Branch Office of Bali Province.

Keywords: ethical sensitivity, moral reasoning, quality of internal audit
\end{abstract}

\section{PENDAHULUAN}

Audit internal atau pemeriksaan intern merupakan fungsi penilaian yang independen dalam suatu organisasi untuk menguji dan mengevaluasi kegiatan organisasi yang dilaksanakan (Atqatia, 2015). Tanggung jawab audit internal mencakup tentang pemeriksaan serta penilaian atas control, kinerja dan tata kelola 
Ida Ayu Pradnyani Wedhasari dan Ida Bagus Putra Astika. Moral...

(Agung, 2016). Kesalahan manajemen suatu perusahaan dalam mengelola sumber daya dapat membuat perusahaan tersebut mengalami kerugian yang cukup besar, kerugian akibat proses produksi yang salah, perekayasaan, pemasaran, atau pengelolaan persediaan bisa jadi besar di bandingkan kerugian akibat kelemahan di bidang keuangan (Sawyer, 2009:7). Hal tersebut menunjukan bahwa kebutuhan akan audit internal semakin meningkat, yang berarti peranan auditor internal menjadi sangat penting.

Badan Usaha Milik Negara (BUMN) dan Badan Usaha Milik Daerah (BUMD) di Indonesia secara umum adalah organisasi bisnis yang berorientasi untuk pasar lokal. Dalam BUMN dan BUMD diperlukan juga pengawasan terhadap pengalokasian dana yang telah di berikan pemerintah pusat dan daerah agar lebih transparan. Tanggung jawab atas pengelolaan BUMN dan BUMD bukan hanya terhadap pemerintah akan tetapi kepada masyarakat Indonesia pada umumnya (Fasial, 2007). Keberadaan auditor internal yang ada di BUMN khususnya PT. Bank BRI Persero. Tbk, dapat membantu manajemen dalam mempertanggung jawabkan pengelolaannya dalam fungsi pengawasan dan seharusnya mampu membantu perusahaan dalam mencapai suatu sistem tata kelola yang baik (good corporate governance). Sayangnya BUMN dan BUMD belum lepas dari beberapa kasus yang secara tidak langsung dapat merugikan negara (Mukino et al., 2016).

Audit internal atau pemeriksaan intern merupakan fungsi penilaian yang independen dalam suatu organisasi untuk menguji dan mengevaluasi kegiatan organisasi yang dilaksanakan (Atqatia, 2015). Tanggung jawab audit internal 
mencakup tentang pemeriksaan serta penilaian atas control, kinerja dan tata kelola (Agung, 2016). Kesalahan manajemen suatu perusahaan dalam mengelola sumber daya dapat membuat perusahaan tersebut mengalami kerugian yang cukup besar, kerugian akibat proses produksi yang salah, perekayasaan, pemasaran, atau pengelolaan persediaan bisa jadi besar di bandingkan kerugian akibat kelemahan di bidang keuangan (Sawyer, 2009:7). Hal tersebut menunjukan bahwa kebutuhan akan audit internal semakin meningkat, yang berarti peranan auditor internal menjadi sangat penting.

Auditor internal adalah auditor yang bekerja dalam perusahaan (perusahaan negara maupun perusahaan swasta),tugas pokoknya yaitu menentukan apakah kebijakan dan prosedur yangditetapkan oleh manajemen puncak telah dipatuhi (Mulyadi, 2016:112). Menentukan baik atau tidaknya penjagaan terhadap kekayaan organisasi, menentukan efisiensi dan efektivitas prosedur kegiatan organisasi, serta menentukan keandalan informasi yang dihasilkan oleh berbagai bagian organisasi.Seseorang baru dapat menjadi auditor internal jika mempunyai pengetahuan yang memadai dalam bidang tugasnya, memiliki kemampuan mempertahankan kualitas profesionalnya melalui pendidikan profesi lanjutan yang berkesinambungan serta dapat berkomunikasi dengan baik lisan maupun tulisan (Aida et al., 2015).

Internal audit merupakan sumber informasi yang penting bagi auditor eksternal Badan Pemeriksa Keuangan (BPK) dan menjadi ujung tombak untuk meningkatkan transparansi dan akuntabilitas dalam pengelolaan dan pengawasan perusahaan. Hasil audit yang berkualitas merupakan sumber informasi penting 
Ida Ayu Pradnyani Wedhasari dan Ida Bagus Putra Astika. Moral...

dalam memberikan keyakinan kepada pihak perusahaan dan BPK (Finty dan Maria, 2017). Pengelolaan dan pengawasan keuangan perusahaan yang baik harus didukung audit sektor publik yang berkualitas, jika kualitas audit sektor publik rendah, kemungkinan memberikan kelonggaran terhadap perusahaan melakukan penyimpangan-penyimpangan kebijakan.

Seorang auditor harus memperhatikan kualitas auditnya, karena dengan kualitas audit yang tinggi diharapkan dapat menghasilkan laporan keuangan yang dapat dipercaya oleh pengguna informasi keuangan (Sudarshan, 2014). Definisi internal auditor yang diberikan oleh the Institute of Internal Auditors (IIA) dalam Statement of Responsibilities of Internal Auditing. Audit internal adalah fungsi penilaian independen yang dibentuk dalam suatu organisasi untuk menguji dan mengevaluasi kegiatan perusahaan sebagai layanan untuk kepentingan perusahaan (Roger, 2015). Tujuan dari audit internal adalah Tujuan ini, audit internal membantu dengan analisis, penilaian, rekomendasi, nasihat, dan informasi mengenai ulasan kegiatan perusahaan (Hasnah et al. 2015).

Kualitas audit yang baik dipengaruhi oleh moral reasoning (Finty \& Maria, 2017). Menurut Agung (2016) moral reasoning didefinisikan sebagai alasan yang mendasari seseorang dalam melakukan suatu tindakan atau alasan yang mendasari seseorang dalam membenarkan ataupun mengkritik suatu perbuatan. Seorang auditor yang memiliki moral reasoning yang tinggi, akan lebih tepat dalam melakukan audit judgement, sehingga kualitas audit yang dihasilkan juga akan semakin baik. Penelitian Ceacilia et al (2016) menemukan bahwa moral reasoning memiliki pengaruh yang positif dan signifikan terhadap kualitas audit. 
Namun berbeda dengan hasil penelitian yang dilakukan oleh Deasy (2013) yang menyimpulkan bahwa variabel moral reasoning tidak berpengaruh terhadap kualitas audit.

Seseorang internal auditor dalam pelaksanaan audit harus memiliki sikap sensitivitas etis dalam melaksanakan tugasnya (Finty dan Maria, 2017). Sensitivitas etis (ethical sensitivity) ini sangat penting dimiliki oleh setiap individu untuk mengukur tingkat kepekaan terhadap nilai-nilai yang ada baik di dalam maupun di luar lingkungan mereka untuk mengambil keputusan (Hasnah et al., 2015). Riset di bidang akuntansi telah difokuskan pada kemampuan para akuntan dalam membuat keputusan etika dan berperilaku etis. Faktor penting dalam penilaian dan perilaku etis adalah kesadaran para individu bahwa mereka adalah agen moral. Kemampuan untuk menyadari adanya nilai-nilai etik atau moral dalam suatu keputusan inilah yang disebut dengan Sensitivitas Etis (Amanuddin et al., 2015). Setiap orang pasti mempunyai sensitivitas terhadap etika, terutama pada seorang auditor karena mereka mendapat ilmu tentang etika di dunia pekerjaan.

Tentu saja tingkat sensitivitas antar individu berbeda-beda. Tingkat sensitivitas biasanya dipengaruhi oleh beberapa faktor diantaranya orientasi etika, komitmen profesional, komitmen organisasional, budaya atau kultur lingkungan, dan karakter personal seorang auditor. Penelitian Atqatia (2015) menemukan bahwa ethical sensitivity memiliki pengaruh yang positif pada kualitas audit. Hasil penelitian yang dilakukan oleh Betti (2014), Ega dan Siti (2013) menyimpulkan bahwa variabel ethical sensitivity tidak berpengaruh pada kualitas audit. 
Ida Ayu Pradnyani Wedhasari dan Ida Bagus Putra Astika. Moral...

Mengingat pentingnya auditor internal bagi kepentingan manajemen perusahaan, maka perlu dilakukan penelitian mengenai kualitas auditor yang terdapat di dalam perusahaan itu sendiri (Betti, 2014). Kualitas auditor tersebut dapat berkaitan dengan moral reasoning dan ethical sensitivity yang berada di dalamnya. Kualitas auditor penting bagi manajemen perusahaan dan auditor agar dapat mengetahui apakah moral reasoning dan ethical sensitivity dapat mempengaruhi kualitas auditor pada suatu perusahaan. Adapun rumusan masalah dalam penelitian ini sebagai berikut: 1) Apakah ethical sensitivity berpengaruh pada kualitas audit di PT. Bank BRI Kantor Cabang se-Provinsi Bali? 2) Apakah moral reasoning memoderasi pengaruh ethical sensitivity pada kualitas audit di PT. Bank BRI Kantor Cabang se-Provinsi Bali?

Teori keagenan menjelaskan hubungan antara agent (pihak manajemen suatu perusahaan) dengan principal (pemilik). Hubungan agensi ada ketika salah salah satu pihak (principal) menyewa pihak lain (agent) untuk melaksanakan suatu jasa, dan dalam hal itu, mendelegasikan wewenang untuk membuat keputusan kepada agen tersebut (Anthony dan Govindarajan, 2011:269). Principal merupakan pihak yang memberikan amanat kepada agent untuk melakukan suatu jasa atas nama principal, sementara agent adalah pihak yang menerima mandat, dengan demikian dapat disimpulkan agent bertindak sebagai pihak yang mengevaluasi informasi (Jaspal, 2013).Belkaoui (2011:186) menyatakan bahwa teori agensi berawal dengan adanya penekanan pada kontrak sukarela yang timbul diantara berbagai pihak organisasi sebagai suatu solusi yang efisien terhadap konflik kepentingan tersebut.Hubungan agensi dikatakan telah terjadi ketika suatu 
kontrak antara seseorang (atau lebih), seorang principal dan seorang agent untuk memberikan jasa demi kepentingan principal termasuk melibatkan adanya pemberian delegasi kekuasaan pengambilan keputusan kepada agent. Baik principal maupun agen diasumsikan untuk termotivasi hanya oleh kepentingannya sendiri, yaitu untuk memaksimalkan kegunaan subjektif mereka dan juga untuk menyadari kepentingan mereka bersama.Untuk mengetahui konflik kepentingan antara principal dan agent, maka principal menggunakan pihak independen untuk mengawasi (monitoring) terhadap perusahaannya. Pihak independen tersebut adalah auditor yang bertanggung jawab dalam pemeriksaan dan penilaian atas kontrol, kinerja, dan tata kelola (governance) perusahaan publik maupun privat. Aspek keuangan hanyalah salah satu aspek saja dalam lingkup pekerjaan audit.

Theory of Reasoned Action (TRA) pertama kali diperkenalkan oleh Martin Fishbein dan Ajzen dalam (Ceaciliaet al., 2016). Teori ini menghubungkan antara keyakinan (belief), sikap (attitude), kehendak (intention) dan perilaku (behavior). Kehendak merupakan prediktor terbaik perilaku, artinya jika ingin mengetahui apa yang akan dilakukan seseorang, cara terbaik adalah mengetahui kehendak orang tersebut. Namun, seseorang dapat membuat pertimbangan berdasarkan alasan-alasan yang sama sekali berbeda (tidak selalu berdasarkan kehendak). Konsep penting dalam teori ini adalah fokus perhatian (salience), yaitu mempertimbangkan sesuatu yang dianggap penting.Theory of Reasoned Action (TRA) terkait sikap moral reasoning sebagai alasan moral yang diperoleh dari proses pembelajaran dan penalaran ilmiah yang dilakukan seseorang (auditor internal), ketika pertimbangan moral telah dilaksanakan dengan baik dalam 
Ida Ayu Pradnyani Wedhasari dan Ida Bagus Putra Astika. Moral...

membuat setiap keputusan, maka mutu pekerjaan dengan sikap sensitivitas etis (ethical sensitivity) untuk mengukur tingkat kepekaan terhadap nilai-nilai yang ada di dalam pelaksanaan audit (Ceaciliaet al., 2016).

Kualitas audit merupakan kemampuan dari seorang auditor dalam melaksanakan tugasnya, dimana dalam melakukan audit seorang auditor dapat menemukan kesalahan klien dan melaporkannya (De Angelo, 1981) dalam (Ahmed et al., 2013). Seorang akuntan publik dalam menjalankan tugas auditnya harus berpegang pada Standar Profesional Akuntan Publik (SPAP) yang berlaku, harapannya audit dapat mengurangi ketidakselarasan kepentingan antara manajemen dan para pemegang saham. Dengan dipatuhinya standar dan prinsip yang berlaku, sehingga tujuan yang inginkan akan tercapai yaitu audit yang berkualitas. Dalam penelitian yang dilakukan oleh (Fan-Hua et al., 2015) ada lima hal yang diperkirakan mempunyai hubungan dengan kualitas audit yaitu (1) pemahaman terhadap sistem informasi akuntansi klien, (2) tingkat ketepatan waktu penyelesaian audit, (3) tingkat kepatuhan terhadap SPAP, (4) tingkat kepercayaan terhadap pernyataan klien, dan (5) tingkat kehati-hatian pengambilan keputusan.

Teori perkembangan moral berusaha untuk menjelaskan rerangka yang mendasari pengambilan keputusan individu dalam konteks dilema etika. Tujuan teori ini adalah memahami proses penalaran kognitif seorang individu dalam mengatasi dilema etika, bukan untuk menilai benar atau salah (Sudarshan, 2014). Jadi moral adalah sikap baik-buruknya, bukan benar atau salah seseorang dalam berhubungan dengan kelompok atau masyarakat (Paneeda et al. 2015). 
Sudarshan (2014) menjelaskan pengertian moral menggunakan istilahistilah seperti moral-reasoning, moral-thingking, dan moral-judgement, sebagai istilah-istilah yang mempunyai pengertian sama dan digunakan secara bergantian, istilah tersebut dialih bahasakan menjadi penalaran moral. Penalaran moral dipandang sebagai suatu struktur pemikiran bukan isi.Dengan demikian penalaran moral bukanlah tentang apa yang baik atau yang buruk, tetapi tentang bagaimana seseorang berpikir sampai pada keputusan bahwa sesuatu adalah baik atau buruk (Sudarshan, 2014). Penalaran-penalaran moral inilah yang menjadi indikator dari tingkatan atau tahapan kematangan moral. Memperhatikan penalaran mengapa suatu tindakan salah, akan lebih memberi penjelasan daripada memperhatikan tindakan (perilaku) seseorang atau bahkan mendengar pernyataan bahwa sesuatu itu salah (Atqatia, 2015).

Melalui hasil penelitian Emine et al (2016) menyatakan ethical sensitivty (sensitivitas etis) diukur dengan memodifikasi skenario sensitivitas etis (Shaub, 1989), yaitu: 1) Pengenalan individu akan keberadaan masalah etis dan pengevaluasian pengaruh pilihan perilaku potensial pada kesejahteraan pihak yang berimbas. 2) Penentuan perilaku moral secara ideal yang sesuai untuk sebuah situasi. 3) Keputusan pada tindakan yang dimaksud berkaitan dengan berbagai hasil yang dinilai dan implikasi moralnya. 4) Pelaksanaan perilaku yang dimaksud tersebut tidak melanggar kode etik. Maka dapat disimpulkan bahwa sensitivitas merupakan tingkat kepekaan seseorang dalam merespon kejadian atau peristiwa tertentu. Jadi, Sensitivitas Etis dapat diartikan sebagai kesadaran individu dalam 
Ida Ayu Pradnyani Wedhasari dan Ida Bagus Putra Astika. Moral...

menilai perilaku etis. Kesadaran individu tersebut dapat dinilai melalui kemampuan untuk menyadari adanya nilai-nilai etis dalam suatu keputusan.

Auditor adalah seorang yang memiliki kualifikasi tertentu dalam melakukan audit atas laporan keuangan dan kegiatan suatu perusahaan atau organisasi. Mulyadi (2016) auditor dapat dibedakan menjadi tiga jenis, antara lain: 1) Auditor pemerintah adalah auditor yang bertugas melakukan audit atas keuangan Negara pada instansi-instansi pemerintah. Di Indonesia audit ini dilakukan oleh Badan Pemeriksaan Keuangan (BPK). 2) Eksternal auditor atau akuntan public adalah seorang praktisi dan gelar professional yang diberikan kepada akuntan di Indonesia yang telah mendapat izin untuk memberikan jasa audit umum dan review atas laporan keuangan, audit kinerja, dan audit khusus serta jasa nonassurancce seperti jasa konsultasi, jasa kompilasi, jasa perpajakan. Praktik akuntan publik harus dilakukan melalui suatu Kantor Akuntan Publik (KAP). 3) Auditor internalmerupakan auditor yang bekerja suatu perusahaan dan oleh karenanya berstatus sebagai pegawai pada perusahaan tersebut.

Emine et al (2016) menyatakan dalam perusahaan harus mampu meningkatkan iklim keterbukaan, integritas, dan akuntabilitas sesuai dengan prinsip-prinsip dalam meningkatkan kualitas audit. Penelitian (Atqatia, 2015) menemukan bahwa ethical sensitivity memiliki pengaruh yang positif dan signifikan terhadap kualitas audit. Hasil penelitian yang dilakukan oleh (Betti, 2014) menyimpulkan bahwa variabel ethical sensitivity berpengaruh pada kualitas audit. Ega dan Siti (2013) membuktikan dalam penelitiannya ethical sensitivity memiliki pengaruh positif pada kualitas audit.Ahmed et al (2013) menyatakan 
kualitas audit secara positif dipengaruhi oleh sikap ethical sensitivity seorang auditor.

$\mathrm{H}_{1}$ :ethical sensitivity berpengaruh positif pada kualitas audit.

Seorang auditor internal dengan tingkat moral reasoning tinggi dalam memberikan Persepsi Etis dari kasus pelanggaran etika akan mendasarkan perilaku akuntan tersebut pada prinsip-prinsip moral (Atqatia, 2015). Tinggi rendahnya ethical sensitivityyang dimiliki seorang auditor internal salah satunya dipengaruhi oleh moral reasoning, dikarenakan moral reasoning dapat menghasilkan tingkat ethical sensitivityyang tinggi ataupun rendah dan selanjutnya dapat mempengaruhi kualitas audit seorang internal auditor. Penelitian Hasnahet al (2015) membuktikan moral reasoning mampu memoderasi pengaruh positif ethical sensitivity pada kualitas audit. Paneeda et al (2015) menyatakan moral reasoning mampu memperkuat pengaruh positif ethical sensitivitypada kualitas audit.

$\mathrm{H}_{2}$ :moral reasoningmemoderasi pengaruh positif ethical sensitivity pada kualitas audit.

\section{METODE PENELITIAN}

Desain penelitian yang digunakan dalam penelitian ini adalah pendekatan kuantitatif yang berbentuk asosiatif. Sugiyono (2015) menyatakan bahwa penelitian asosiatif adalah penelitian yang bertujuan untuk mengetahui hubungan dua variabel atau lebih.Penelitian ini berbentuk kausalitas yaitu menganalisis hubungan sebab akibat antara variabel independen dan variabel dependen, sertamenganalisis variabel moderasi (memperkuat atau memperlemah) hubungan langsung variabel bebas dengan variabel terikat (Sugiyono,2015). 


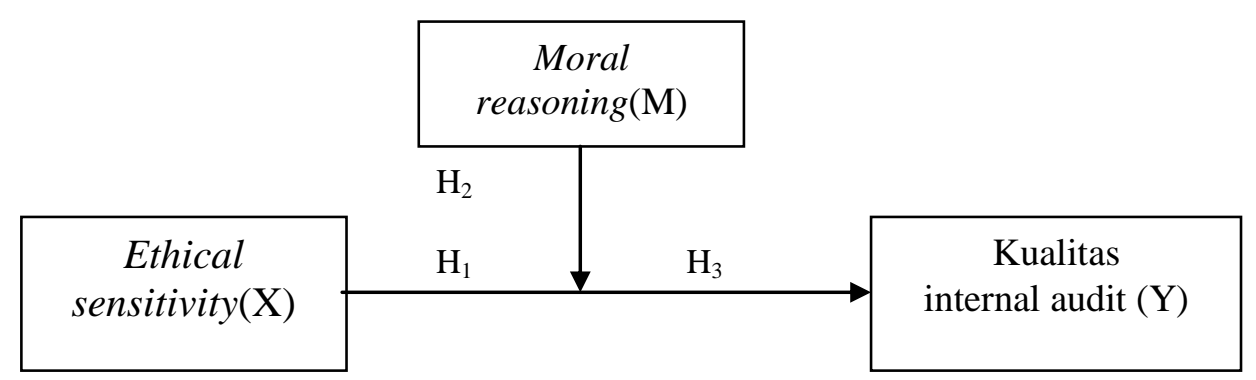

\section{Gambar 1 Desain Penelitian}

Penelitian ini dilakukan di PT. Bank BRI dengan mewilayahi cabang Renon, Gajah Mada, Gatot Subroto, Kuta, Tabanan, Negara, Singaraja, Gianyar, Ubud, Klungkung dan Karangasem dengan masing-masing cabang mewilayahi unit kerja, kantor kas dan teras di daerah masing-masing tahun 2017. Objek penelitian dalam penelitian ini adalah kualitas audit pada seluruh PT. Bank BRI yang dipengaruhi oleh ethical sensitivity dengan moderasi moral reasoning.

Variabel merupakan suatu sifat yang dapat memiliki berbagai macam nilai. Berdasarkan hipotesis yang telah dikemukakan, maka variabel yang akan dianalisis dikelompokkan sebagai berikut: 1)Variabel Bebas (X) dalam penelitian ini adalahethical sensitivity. 2) Variabel Terikat (Y) dalam penelitian ini adalah kualitas audit. 3) Variabel Moderasi (M) adalah moral reasoning.

Populasi adalah wilayah generalisasi yang terdiri atas objek atau subjek yang mempunyai kualitas dan karakteristik tertentu yang ditetapkan oleh peneliti untuk dipelajari dan kemudian ditarik kesimpulannya (Sugiyono, 2015:115). Populasi dalam penelitian ini adalah seluruh internal auditor PT. Bank BRI yang tergabung dalam Institut Auditor Publik Indonesia.

Sampel jenuh adalah teknik penentuan sampel apabila semua anggota populasi digunakan sebagai sampel (Sugiyono, 2015:68). Pemilihan sampel 
initelah mewakili populasi, dengan batas minimum sampel suatu penelitian adalah sebanyak 50 sampel. Jumlah responden yang akan dilibatkan sebagai sampel dalam penelitian ini adalah sebanyak 50 responden dengan menggunakan metode sensus (Sugiyono, 2015:17).

Metode pengumpulan data yang digunakan dalam penelitian ini yaitu, teknik kuesioner, wawancara dan studi pustaka (library research). Teknik Kuesioner adalah teknik pengumpulan data yang dilakukan dengan cara memberikan seperangkat pertanyaan atau pernyataan tertulis kepada responden untuk dijawab (Sugiyono, 2015:135). Untuk masing-masing pernyataan dalam kuesioner, diberikan skor 1-5 berdasarkan skala likert. Setiap jawaban kuesioner mempunyai bobot atau skor nilai dengan skala Likert sebagai berikut : untuk jawaban sangat setuju (SS), mendapat skor 5, untuk jawaban setuju (S), mendapat skor 4, untuk jawaban netral (N), mendapat skor 3, untuk jawaban tidak setuju (TS), mendapat skor 2 dan untuk jawaban sangat tidak setuju (STS), mendapat skor 1.

Wawancara dimana teknik pengumpulan data ini peneliti mengajukan beberapa pertanyaan langsung terhadap responden yaitu internal auditor yang bekerja pada PT. Bank BRI, biasa disebut dengan Resident Audit (RA) dan Recident Audit Unit (RAU).Studi Pustaka (Library research), peneliti memperoleh data yang berkaitan dengan masalah yang sedang diteliti melalui buku, jurnal, skripsi, tesis, internet, dan perangkat lain yang berkaitan dengan judul penelitian. 
Ida Ayu Pradnyani Wedhasari dan Ida Bagus Putra Astika. Moral...

Teknik perhitungan dan analisis data menggunakan Moderating Regression Analysis. Moderating Regression Analysis dinyatakan dalam bentuk regresi berganda dengan persamaan mirip regressi polynomial yang menggambarkan pengaruh nonlinier (Ghozali, 2009; 47) yang dinyatakan dalam bentuk model persamaan sebagai berikut.

$\mathrm{Y}=\alpha+\beta_{1} \mathrm{X}_{1+} \beta_{2}\left(\mathrm{X}_{1} \mathrm{M}\right)+\mathrm{e}$

Keterangan:

$\mathrm{Y} \quad=$ kualitas audit

$\alpha \quad=$ konstanta

$\beta_{1,} \beta_{2}$, = koefisien regresi masing-masing variabel independen

$\mathrm{X} \quad=$ ethical sensitivity

$\mathrm{M} \quad=$ moral reasoning

e $\quad=$ error term yaitu faktor kesalahan dalam penelitian

\section{HASIL DAN PEMBAHASAN}

Data dikumpulkan dengan menyebar kuesioner ke dua belas kantorPT. Bank BRI Kantor Cabang se-Provinsi Bali. Kuesioner yang disebar ke responden sebanyak50 kuesioner dan yang terkumpul sebanyak 50. Tidak terdapat kueisoner yang tidak kembali, tidak terdapat kuesioner yang digugurkan, sehingga secara keseluruhan jumlah kuesioner yang layak digunakan untuk dianalisis sebanyak 50 kuesioner.

Karakteristik responden penelitian ini merupakan profil dari 50 responden yang berpartisipasi dalam pengisian kuesioner. Karakteristik responden penelitian meliputi jenis kelamin, jenjang pendidikan dan lama bekerja. Proporsi auditor laki-laki dan perempuan berdasarkan jenis kelamin. Dapat diketahui jumlah auditor laki-laki sebanyak 37 orang responden (74\%) dan auditor perempuan sebanyak 13 orang responden (26\%). Ini menandakan bahwa sebagai seorang 
auditor internal yang memiliki tugas cukup berat dalam melaksanakan audit, lebih banyak laki-laki yang menggelutinya karena terkesan berani mengambil risiko tanpa memperdulikan tekanan dari pihak-pihak tertentu.

Responden yang memiliki tingkat pendidikan Diploma sebanyak 4 orang (8\%), S1 sebanyak 32 orang (64\%) dan S2 sebanyak 14 orang (28\%). Ini menandakan seorang auditor juga ditentukan oleh tingkat pendidikannya, yang mengartikan bahwa semakin baik tingkat pendidikan seorang auditor dapatmenunjukkan tingkat kinerjanya dalam melakukan audit dengan kualitas yang lebih baik serta pengetahuan yang lebih luas.

Responden yang tergabung dalam tim audit kurang dari atau sama dengan lima tahun sebanyak 17 orang (34\%). Responden yang tergabung dalam tim audit lebih dari lima tahun sampai 10 tahun sebanyak 33 orang (66\%). Berdasarkan data tersebut bisa kita lihat seluruh responden sudah pernah tergabung dalam tim audit. Hal ini menunjukan bahwa responden yang digunakan dalam penelitian ini layak digunakan dan menunjukkan data yang valid, karena dengan bergabungnnya dalam tim audit tentunya akan menambah atau meningkatkan standar kinerja auditor internal tersebut.

Untuk mengukur nilai sentral dari distribusi data dapat dilakukan dengan pengukuran rata-rata (mean) sedangkan standar deviasi merupakan perbedaan nilai data yang diteliti dengan nilai rata-ratanya. Hasil statistik deskriptif dapat dilihat pada Tabel 1 . 
Tabel 1.

Hasil Statistik Deskriptif

\begin{tabular}{lccccc}
\hline Variabel & N & Min. & Max. & Mean & $\begin{array}{l}\text { Std. } \\
\text { Deviasi }\end{array}$ \\
\hline Ethical Sensitivity & 50 & 11 & 16 & 14,52 & 1,529 \\
Moral Reasoning & 50 & 18 & 25 & 22,74 & 1,827 \\
$\begin{array}{l}\text { Ethical Sensitivity- } \\
\text { Reasoning }\end{array}$ & 50 & 209 & 384 & 329,68 & 39,974 \\
Kualitas Internal audit & 50 & 14 & 27 & 21,66 & 2,897 \\
Sumber: Data Diolah, 2017 & & & & &
\end{tabular}

Tabel 1.dapat dilihat bahwa variabel ethical sensitivity (X) memiliki nilai minimum sebesar 11, nilai maksimum sebesar 16, mean sebesar 14,52, dan standar deviasi sebesar 1,529. Ini berarti bahwa terjadi perbedaan nilaiethical sensitivity yang diteliti terhadap nilai rata-ratanya sebesar 1,529.

Variabel moral reasoning $(\mathrm{M})$ memiliki nilai minimum sebesar 18, nilai maksimum sebesar 25 , mean sebesar 22,74, dan standar deviasi sebesar 1,827. Ini berarti bahwa terjadi perbedaan nilai moral reasoning yang diteliti terhadap nilai rata-ratanya sebesar 1,827 .

Variabel ethical sensitivity (X) - moral reasoning $(\mathrm{M})$ memiliki nilai minimum sebesar 209, nilai maksimum sebesar 384, mean sebesar 329,68, dan standar deviasi sebesar 39,974. Ini berarti bahwa terjadi perbedaan nilai ethical sensitivity - moral reasoning yang diteliti terhadap nilai rata-ratanya sebesar 39,974. Variabel kualitas internal audit (Y) memiliki nilai minimum sebesar 14, nilai maksimum sebesar 27, mean sebesar 21,66, dan standar deviasi sebesar 2,897. Ini berarti bahwa terjadi perbedaan nilai kualitas internal audit (Y) yang diteliti terhadap nilai rata-ratanya sebesar 2,897. Pengujian validitas tiap butir digunakan analisis item yaitu mengkorelasikan skor tiap item dengan skor total 
item. Jika korelasi item terhadap skor total lebih besar dari r kritis $(0,30)$ maka instrumen dikatakan valid yang disajikan pada Tabel 2.berikut:

Tabel 2. Hasil Uji Validitas

\begin{tabular}{lll}
\hline Variabel & Instrumen & Pearson Correlation \\
\hline \multirow{3}{*}{ Ethicalsensitivity $(\mathrm{X})$} & $\mathrm{X}_{1.1}$ & 0,822 \\
& $\mathrm{X}_{1.2}$ & 0,842 \\
& $\mathrm{X}_{1.3}$ & 0,854 \\
& $\mathrm{X}_{1.4}$ & 0,858 \\
& $\mathrm{M}_{2.1}$ & 0,557 \\
& $\mathrm{M}_{2.2}$ & 0,849 \\
Moral reasoning $(\mathrm{M})$ & $\mathrm{M}_{2.3}$ & 0,695 \\
& $\mathrm{M}_{2.4}$ & 0,716 \\
& $\mathrm{M}_{2.5}$ & 0,676 \\
& $\mathrm{M}_{2.6}$ & 0,790 \\
& $\mathrm{Y}_{1}$ & 0,822 \\
& $\mathrm{Y}_{2}$ & 0,850 \\
& $\mathrm{Y}_{3}$ & 0,702 \\
& $\mathrm{Y}_{4}$ & 0,705 \\
& $\mathrm{Y}_{5}$ & 0,848 \\
& $\mathrm{Y}_{6}$ & 0,901 \\
\hline
\end{tabular}

Sumber: Data Diolah, 2017

Tabel 2.dibawah terlihat variabel ethical sensitivity memiliki pearson correlation dari $0,822-0,858(>0,30)$, hal ini berarti bahwa pernyataan tersebut valid. Variabel moral reasoning memiliki pearson correlation dari $0,557-0,849$ $(>0,30)$, hal ini berarti bahwa pernyataan tersebut valid. Variabel kualitas internal audit memiliki pearson correlation dari $0,702-0,901(>0,30)$, hal ini berarti bahwa pernyataan dalam kuesioner adalah valid.

Pengujian reliabilitas dalam penelitian ini menggunakan metode Cronbach's Alpha. Instrumen dikatakan reliabel untuk mengukur variabel bila berada di atas angka 0,60. Hasil pengujian reliabilitas instrumen dapat dilihat pada Tabel 3. 
Tabel 3.

Hasil Uji Reliabilitas

\begin{tabular}{ll}
\hline Variabel & Cronbach's Alpha \\
\hline Ethical sensitivity $(\mathrm{X})$ & 0,863 \\
Moral reasoning $(\mathrm{M})$ & 0,804 \\
Kualitas internal audit (Y) & 0,892 \\
\hline Sumber: Data Diolah, 2017 &
\end{tabular}

Sumber: Data Diolah, 2017

Tabel 3.menjelaskan bahwa nilai alpha di hitung masing-masing variabel lebih besar dari $\mathrm{R}$ alpha tabel yaitu 0,60 sehingga dapat disimpulkan bahwa pernyataan dalam kuesioner tersebut reliabel.

Model regresi yang baik adalah model regresi yang di dalamnya tidak terdapat masalah data yang distribusinya normal, masalah multikolinearitas, dan masalah heteroskedastisitas. Adapun pengujian asumsi klasik yang dilakukan yaitu: uji normalitas, uji multikolinearitas, dan uji heteroskedastisitas. Tabel 4. Menunjukkah hasil uji asumsi klasik.

Tabel 4.

Hasil Uji Asumsi Klasik

\begin{tabular}{|c|c|c|}
\hline Uji Asumsi Klasik & Hasil Uji & Keterangan \\
\hline Uji Normalitas & $\mathrm{p}(0,150)>0,05$ & Berdistribusi normal \\
\hline Uji Multikolinearitas & $\begin{array}{l}\text { Tolerance } \quad(0,006) ; \quad(0,010) \\
<0,1 \\
\text { VIF }(153,893) ;(98,047)>10\end{array}$ & Tidak ada multikolinearitas \\
\hline Uji Heteroskedastisitas & $\mathrm{p}(0,440) ;(0,357)$ & $\begin{array}{l}\text { Tidak terjadi } \\
\text { heteroskedastisitas }\end{array}$ \\
\hline
\end{tabular}

Sumber: Data diolah, 2017

Moderating Regression Analysis dinyatakan dalam bentuk regresi berganda dengan persamaan mirip regressi polynomial yang menggambarkan moralreasoningmemoderasi pengaruh ethical sensitivitypada kualitas internal audit di PT. Bank BRI Kantor Cabang se-Provinsi Bali dengan bantuan program 
Statistical Package of Social Science (SPSS). Hasil pengujian disajikan dalam hasil uji nilai selisih mutlak pada Tabel 5. berikut ini:

Tabel 5.

Hasil Pelaporan Analisis MRA

\begin{tabular}{|c|c|c|c|c|c|}
\hline \multirow{2}{*}{ Model } & \multicolumn{2}{|c|}{$\begin{array}{c}\text { Unstandardized } \\
\text { Coefficients }\end{array}$} & \multirow{2}{*}{$\begin{array}{c}\text { Standardized } \\
\text { Coefficients } \\
\text { Beta }\end{array}$} & \multirow{2}{*}{ Sig. } & \multirow{2}{*}{$\begin{array}{l}\text { Hasil Uji } \\
\text { Hipotesis }\end{array}$} \\
\hline & B & Std. Error & & & \\
\hline (Constant) & $-74,290$ & 33,858 & & 0,033 & \\
\hline Ethical Sensitivity (X1) & 6,008 & 2,236 & 3,170 & 0,010 & $\mathrm{H}_{1}$ Diterima \\
\hline $\begin{array}{l}\text { Ethical Sensitivity - } \\
\text { Moral Reasoning }\end{array}$ & 0,204 & 0,099 & 2,809 & 0,045 & $\mathrm{H}_{2}$ Diterima \\
\hline Sig. F: & & 0,000 & & & \\
\hline$R$ Square & & 0,584 & & & \\
\hline Adjusted $R_{\text {square: }}$ & & 0,557 & & & \\
\hline
\end{tabular}

Sumber : Data diolah, 2017

Persamaan regresi pada Tabel 5dapat dijelaskan untuk setiap variabel halhal sebagai berikut:

$$
\mathrm{Y}=-74,290+6,008 \mathrm{X}+3,334 \mathrm{M}_{1}+0,204 \mathrm{ZXM}
$$

Berdasarkan model persamaan regresi tersebut dapat dijelaskan bahwa nilai konstanta dengan adanya moderasi moral reasoningadalah sebesar 74,290,artinya apabila variabel ethical sensitivitydan moral reasoningdan interaksi antara variabel independen dengan moderasi ada atau sama dengan 0 (nol), maka kualitas internal audit mengalami penurunan pada PT. Bank BRI Kantor Cabang se-Provinsi Bali.

Nilai Koefisien $\beta_{1}$ yang diperoleh sebesar 6,008 menunjukan bahwa pengaruh antara variabel ethical sensitivity dan kualitas internal audit bersifat 
Ida Ayu Pradnyani Wedhasari dan Ida Bagus Putra Astika. Moral...

positif. Artinya peningkatan pada ethical sensitivityakan diikuti oleh peningkatan pada kualitas internal audit diPT. Bank BRI Kantor Cabang se-Provinsi Bali. Nilai Koefisien $\beta_{2}$ yang diperoleh sebesar 0,204 menunjukan bahwa interaksi antara variabel moral reasoning dan ethical sensitivitybersifat positif. Artinya interaksi moral reasoning memperkuat pengaruh antara ethical sensitivity pada kualitas internal audit diPT. Bank BRI Kantor Cabang se-Provinsi Bali.

Hasil uji statistik F pada Tabel 5, menunjukan hasil nilai siginifikansi sebesar 0,000 yang lebih kecil dari tingkat $\alpha=0,05$. Hal ini berarti variabel ethical sensitivity dan moral reasoning secara bersamaan berpengaruh pada kualitas internal audit pada PT. Bank BRI Kantor Cabang se-Provinsi Bali. Hal ini mengindikasikan bahwa model yang digunakan dalam penelitian ini layak dipergunakan. Hasil perhitungan uji t dapat dilihat pada Tabel 5. Dari tabel tersebut diketahui bahwa nilai koefisien regresi $\mathrm{X}$ adalah sebesar 2,687 dengan tingkat signifikansi sebesar 0,010 lebih kecil dibandingkan dengan taraf nyata $\alpha=$ 0,05. Hal ini menunjukan bahwa ethical sensitivity berpengaruh positif pada kualitas internal audit diPT. Bank BRI Kantor Cabang se-Provinsi Bali. Semakin tinggi ethicalsensitivity seorang auditor maka kualitas internal audit juga semakin meningkat. Hipotesis yang menyatakan bahwa ethicalsensitivityberpengaruh positif pada kualitas internal audit diterima.

Hasil perhitungan uji t dapat dilihat pada Tabel 5. Dari tabel tersebut diketahui bahwa nilai koefisien regresi ZXM adalah sebesar 2,058 dengan tingkat signifikansi sebesar 0,045 lebih kecil dibandingkan dengan taraf nyata $\alpha=0,05$. Hal ini menunjukan bahwa moral reasoning seorang auditor mampu memperkuat 
pengaruh positif ethica lsensitivity pada kualitas internal audit di PT. Bank BRI Kantor Cabang se-Provinsi Bali, artinya semakin baik moralreasoningseorang auditormaka sikap ethical sensitivity yang dimilikinya semakin baik pula sehingga mampu meningkatkan kualitas internal audit pada PT. Bank BRI Kantor Cabang se-Provinsi Bali. Hipotesis yang menyatakan bahwa moralreasoning memoderasi ethicalsensitivity terhadap kualitas internal audit diterima.

Pengujian koefisien determinasi $\left(\mathrm{R}^{2}\right)$ dilakukan untuk mengetahui seberapa besar variasi variabel dependentakan mampu dijelaskan oleh variabel independennya, sedangkan sisanya dijelaskan oleh sebab-sebab variabel lain di luar model (Ghozali, 2016:97). Nilai adjusted R square model 0,584 atau sebesar $58,4 \%$ artinya sebesar $58,4 \%$ variasi atau perubahan kualitas internal audit dapat dijelaskan oleh variasi variabel dalam model tersebut yaitu ethical sensitivity dan moral reasoning.

\section{SIMPULAN}

Berdasarkan hasil pembahasan analisis data melalui pembuktian terhadap hipotesis dari permasalahan yang diangkat mengenai moral reasoning memoderasi pengaruh ethical sensitivity pada kualitas audit di PT. Bank BRI Kantor Cabang se-Provinsi Bali dapat disimpulkan bahwa Ethical sensitivity berpengaruh positif pada kualitas internal audit di PT. Bank BRI Kantor Cabang se-Provinsi Bali. Hal ini berarti semakin tinggi ethical sensitivity seorang auditor maka kualitas internal audit juga semakin meningkat.

Moral reasoning memoderasi pengaruh positif ethical sensitivity pada kualitas internal audit di PT. Bank BRI Kantor Cabang se-Provinsi Bali. Hal ini 
Ida Ayu Pradnyani Wedhasari dan Ida Bagus Putra Astika. Moral...

berarti semakin baik moral reasoning seorang auditor maka sikap ethical sensitivity yang dimilikinya semakin baik pula sehingga mampu meningkatkan kualitas internal audit pada PT. Bank BRI Kantor Cabang se-Provinsi Bali.Berdasarkan hasil penelitian dan simpulan di atas, maka saran yang dapat disampaikan hasil penelitian ini diharapkan dapat memberikan kontribusi praktis bagi para praktisi auditing khususnya manajemen PT. Bank BRI Kantor Cabang se-Provinsi Bali agar dapat mempertimbangkan karakteristik personal auditor dalam keputusan menetapkan waktu penugasan audit agar tercapai efesiensi audit tanpa mengurangi efektifitas audit. Begitu juga para auditor sebaiknya memperhatikan pentingnya personal yang baik dalam menjalankan audit, dalam hal ini memiliki sikap moral reasoning dan ethical sensitivity agar digunakan sebagai acuan dalam mengambil keputusan sebaik mungkin untuk menghasilkan kualitas audit yang baik. Peneliti diharapkan menggunakan variabel-variabel lain yang mempengaruhui kualitas auditor, karena hasil Adjusted R Square 56,7\% berarti masih ada $43.3 \%$ factor lain yang dapat mempengaruhi kualitas auditor. Peneliti selanjutnya dapat mengambil variabel lainnya selain ethical sensitivity dan moral reasoning, seperti kompetensi, role stress, dengan menerapkan di lokasi penelitian yang lain seperti perbankan, pemerintahan dan lainnya yang berhubungan dengan auditor.

Perilaku moral reasoning yang harus dimiliki oleh seorang auditor internal dalam melaksanakan audit sedapat mungkin memiliki sifat konsekuen dengan melakukan pendekatan yang berorientasi pada tugas (otokrasi, pengawasan dan transaksional) sehingga mampu meminimalkan biaya operasional perusahaan. 
Memiliki sifat ethical sensitivity dengan sikap etis yang berpegang teguh dalam membantu perusahaan mencapai kesejahteraanya, dimana auditor internal bekerja sesuai dengan etika dan aturan yang sudah diterapkan sehingga maksimala dalam melaksanakan audit. Auditor internal dituntut untuk memahami sistem informasi akuntansi dalam melaksanakan pemeriksaan audit, sehingga mampu melakukan pelaporan audit secara maksimal untuk kepentingan pihak perusahaan.

\section{REFERENSI}

Agung Wibowo. 2016. Pengaruh Kode Etik Akuntan, Personal Ethical Philosophy, Corporate Ethical Value Terhadap Persepsi Etis Dan Pertimbangan Etis Auditor (Studi Empiris pada Kantor Akuntan Publik di Jakarta). Jurnal Ilmiah UNTAG Semarang. 3(3): h: 30 - 48

Ahmed Mohamed Alteer, Sofri Bin Yahya, Md Harashid Haron. 2013. Religiosity and Auditors' Ethical Sensitivity at Different Levels of Ethical Climate: A Conceptual Link. American Journal of Economics. 3(5): h: 119-124

Aida Hazlin Ismail, Takiah Mohd Iskandar, Zuraidah Mohd Sanusi and Zaleha Abdul Shukor. 2015. Auditor Ethical Judgements Assesing The Effect of Ethical Sensitivity and Ethical Climate.Journal of Malaysian Accounting Riview. 15(2): h: 185-207

Amanuddin Shamsuddin, Fazliana Azzahara Bt Abd Wahab, Intan Athirah Binti Mohd Fu'ad, Khairunnisa Bt. Azis, Mohammad Adib Bin Mahmood. 2015. Factors That Influence the Ethical Sensitivity of Accounting Students inMalaysian universities.Journal of Education and Social Sciences. 2(1): h: 41-50

Anthony, N. and Govindarajan, V. 2005. "Management control systems", 9 ed. Irwin/McGraw-Hill

Atqatia Sugiharti. 2015. Pengaruh Moral Reasoning dan Ethical Sensitivity Terhadap Persepsi Etis Mahasiswa Akuntansi dengan Gender Sebagai Variabel Moderasi (Studi Empiris Pada Mahasiswa Akuntansi di Perguruan Tinggi Islam dan Perguruan Tinggi Nasional di Daerah Istimewa Yogyakarta). Journal Of Acounting. 2(3): h:1-26

Belkaoui, Ahmed Riahi. 2011. Accounting Theory. UK: Bussines Press Thomson Learning, 4th ed. 
Betti Susanti. 2014. Pengaruh Locus Of Control, Equity Sensitivity, Ethical Sensitivity Dan Gender Terhadap Perilaku Etis Akuntan. Jurnal Accounting Analysis. 4(3): h: 1- 18

Ceacilia Sri Mindarti, Pancawati Hardiningsih, Rachmawati Meita Oktaviani. 2016. Moral Reasoning Memoderasi Kompetensi dan Independensi Terhadap Audit. Jurnal Simposium Nasional Akuntansi. 11(1): h:1-25

Deasy Ariyanti Rahayuningsih. 2013. Kajian Aspek Perilaku Pada Keputusan Akuntan Profesional. Jurnal Ekonomi Akuntansi. 3(5): h: 73-81

De Angelo, L.E. 1981. Auditor Independence, "Low Balling”, and Disclosure Regulation. Journal of Accounting and Ecnomics 3. Agustus. p. 113-127.

Ega Megarina Iswarini dan Siti Mutmainah. 2013. Pengaruh Penalaran Etis dan Faktor-faktor Pribadi Terhadap Sensitivitis Etis pada Mahasiswa Akuntansi. Diponegoro Journal Of Acounting. 2(1): h: 1-11

Emine Yilmaz Karakoc. 2016. The Role of Ethical Sensitivity and Self-Esteem on Academic Performance in Accounting Course. Eurasian Journal of Bussines and Management. 4(2): h: 95-105

Fan-Hua Kung, Cheng-Li Huang. 2015. Auditors' Moral Philosophies and Ethical Beliefs. Journal of Management Decision. 51(4): h: 1-35

Fasial. 2007. Tekanan Pengaruh Sosial dalam Menjelaskan Hubungan Moral Reasoning Terhadap Keputusan Auditor. Jurnal Akuntansi dan Keuangan Indonesia. 4(1): h: 25-46

Finty Udayani, Anak Agung K., dan Maria M. Ratna Sari. 2017. Pengaruh Pengendalian Internal dan Moralitas Individu pada Kecenderungan Kecurangan Akuntansi. Jurnal Akuntansi Universitas Udayana. 18(3): h: 1774-1799

Ghozali, Imam. 2016. Aplikasi Analisis Multivariate dengan Program SPSS. Edisi kc-2. Semarang: Badan Penerbit Universitas Diponegoro.Hasnah Haron, Ishak Ismail and Aw Lo Na. 2015. The Effect of Moral Reasoning, Exposure to Ethics and Perceived Ethical Climate on Ethical Judgement of Auditors in Malaysia. Asian Journal of Business and Accounting. 8(2): h: 25-64

Jaspal Singh. 2013. Determinants of Ethical Sensitivity Among Malaysian AccountingStudents. Journal of Malaysian Accounting Riview. 3(2): h: 132 
Mukino, Edi Purnomo, Irawan Suntoro. 2016. The Application of Moral Reasoning Model to Build Students' Morality and Character in Teaching Civics. Jurnal Studi Sosial. 4(1): h: 42-52

Mulyadi, 2016. Auditing. Edisi ke-6. Jakarta: Salemba Empat.

Paneeda Tangsakul, Phaprukbaramee Ussahawanitchakit. 2015. Moral reasoning of tax auditors in Thailand: an empirical investigation of the antecedents and Consequences. Journal ofBusiness and Management Review. 7(1): h: 134-142

Roger L. Sticher. 2015. An Analysis of How Demographics Affect the Ethical Sensitivity of Accounting Students. Journal of Management Decision. 1(3): h: $85-96$

Sawyer, Lawrence B, Dittenhofer Mortimer A, Scheiner James H, 2009, Internal Auditing, Jilid 1, Edisi 5, Salemba Empat : Jakarta

Sudarshan K. Pillalamarri. 2014. The Role of Moral Reasoning and Order Effects in Ethical Decision Making Ability: The Case of Novice Vs Experienced Accounting Students. Journal of Management Decision. 2(4): h: 1-28

Sugiyono. 2015. Metode Penelitian Bisnis. Bandung: CV. Alfabeta.

The Institute of Auditor internals. (1995). Standars for The Professional Practice of Auditor internaling. The IIA, Florida. 